\title{
Inverted terminal repeats of adeno-associated virus decrease random integration of a gene targeting fragment in Saccharomyces cerevisiae
}

\author{
Alvaro Galli and Tiziana Cervelli
}

\begin{abstract}
Background: Homologous recombination mediated gene targeting is still too inefficient to be applied extensively in genomics and gene therapy. Although sequence-specific nucleases could greatly stimulate gene targeting efficiency, the off-target cleavage sites of these nucleases highlighted the risk of this strategy. Adeno-associated virus (AAV)-based vectors are used for specific gene knockouts, since several studies indicate that these vectors are able to induce site-specific genome alterations at high frequency. Since each targeted event is accompanied by at least ten random integration events, increasing our knowledge regarding the mechanisms behind these events is necessary in order to understand the potential of AAV-mediated gene targeting for therapy application. Moreover, the role of AAV regulatory proteins (Rep) and inverted terminal repeated sequences (ITRs) in random and homologous integration is not completely known. In this study, we used the yeast Saccharomyces cerevisiae as a genetic model system to evaluate whether the presence of ITRs in the integrating plasmid has an effect on gene targeting and random integration.

Results: We have shown that the presence of ITRs flanking a gene targeting vector containing homology to its genomic target decreased the frequency of random integration, leading to an increase in the gene targeting/ random integration ratio. On the other hand, the expression of Rep proteins, which produce a nick in the ITR, significantly increased non-homologous integration of a DNA fragment sharing no homology to the genome, but had no effect on gene targeting or random integration when the DNA fragment shared homology with the genome. Molecular analysis showed that ITRs are frequently conserved in the random integrants, and that they induce rearrangements.
\end{abstract}

Conclusions: Our results indicate that ITRs may be a useful tool for decreasing random integration, and consequently favor homologous gene targeting.

Keywords: Yeast, AAV, ITRs, Homologous recombination, Random integration

\section{Background}

Gene targeting is the process by which exogenously delivered DNA is used to modify a genomic target by homologous recombination. Since in human cells the spontaneous frequency of homologous recombination is on the order of $10^{-6}$, the gene targeting approach is not efficient enough to be applied for clinical use [1]. However, several reports indicate that sequence-specific nucleases, which induce a site-specific double strand

\footnotetext{
* Correspondence: alvaro.galli@ifc.cnr.it; tiziana.cervelli@ifc.cnr.it Yeast Genetics and Genomics Group, Institute of Clinical Physiology, CNR, via Moruzzi 1, 56125 Pisa, Italy
}

\section{() Biomed Central}

(c) 2014 Galli and Cervelli; licensee BioMed Central Ltd. This is an Open Access article distributed under the terms of the Creative Commons Attribution License (http://creativecommons.org/licenses/by/2.0), which permits unrestricted use, distribution, and reproduction in any medium, provided the original work is properly credited. The Creative Commons Public Domain Dedication waiver (http://creativecommons.org/publicdomain/zero/1.0/) applies to the data made available in this article, unless otherwise stated. break in the target DNA, can increase gene targeting efficiency up to 50,000-fold [2]; this approach is thus particularly useful for manipulating primary human cells with therapeutic potential $[3,4]$. Although there has been considerable excitement about the potential application of zinc finger nucleases, since these enzymes allow highly specific, targeted genome modification in live cells [5], several reports show the off-target cleavage sites of these nucleases, highlighting the risk of using this approach [6,7]. Therefore, the search for new tools to improve the efficiency of gene targeting is still very important. Recently, the induction of a site-specific single-strand nick significantly increased gene targeting

aricle, unless otherwise stated. 
[8]. Our previously published studies show that the overexpression or nuclear permeation of the Saccharomyces cerevisiae protein Rad52 strongly increases homologous recombination and gene targeting in HeLa cells $[9,10]$. An alternative method of homologous recombination mediated gene targeting consists of exploiting the recombinogenic nature of the adeno-associated virus (AAV) vector genome [11]. The AAV single stranded (ss) DNA genome contains two overlapping open reading frames flanked by two inverted repeated sequences (ITRs), the only elements required in cis for replication and integration. The Rep open reading frame codes for Rep proteins essential for DNA replication, integration and packaging. The Cap codes for the proteins essential for capsid formation [12]. Vectors based on AAV, which deliver single-stranded, linear DNA genomes, are able to efficiently introduce many types of mutations into homologous target loci at a frequency approaching $1 \%$ in mammalian cells, and are currently used as gene targeting vectors [13-16]. However, using this method, each homologous targeted event occurs within ten random integrations [14]. Recently, by combining AAV technology with zinc finger nucleases, the efficiency of gene targeting increases up to $6 \%$ but most integration events still occur outside the target locus, most likely in naturally occurring DNA doublestrand breaks [7,15-18].

Moreover, AAV-mediated gene targeting has been reported to be less dependent on the extent of homology between the vector and the genome target than other methods [14]. Notably, the presence of the ITRs flanking the gene targeting construct determines increased homologous recombination frequencies [19].
When AAV Rep proteins are expressed, the yeast Saccharomyces cerevisiae is able to replicate the ssDNA genome [20]. The proteins Rep68 and Rep40 are necessary for AAV replication and for site-specific integration $[21,22]$. Rep proteins interact with the Rep-binding element and the terminal resolution site sequences located within the ITRs, to create a nick that may increase the integration $[23,24]$.

In the yeast Saccharomyces cerevisiae, gene targeting is very efficient; it occurs at a frequency of $2-3 \%$ and can be increased up to $25 \%$, whereas random or nonhomologous integration is reported to be less than $0.1 \%$ $[25,26]$. Yeast is an excellent genetic model for understanding the mechanisms and pathways involved in homologous and non-homologous recombination [27-30]. Moreover, yeast has been recently used as a system for studying the potential of a new genome editing approach for site-specific mutagenic and multiple allele replacement [31].

We decided to use the yeast Saccharomyces cerevisiae to evaluate whether the presence of ITRs in the integrating plasmid and the expression of AAV Rep proteins have an effect on gene targeting and random integration. The aim of this study was to assess whether the use of AAV sequences or expression of Rep proteins could be a feasible and valuable tool for increasing gene targeting or decreasing random integration.

\section{Results and discussion}

The presence of ITRs decreased the random integration of a gene targeting construct

AAV vectors are often used for gene targeting experiments in mammalian cells also in combination with zinc
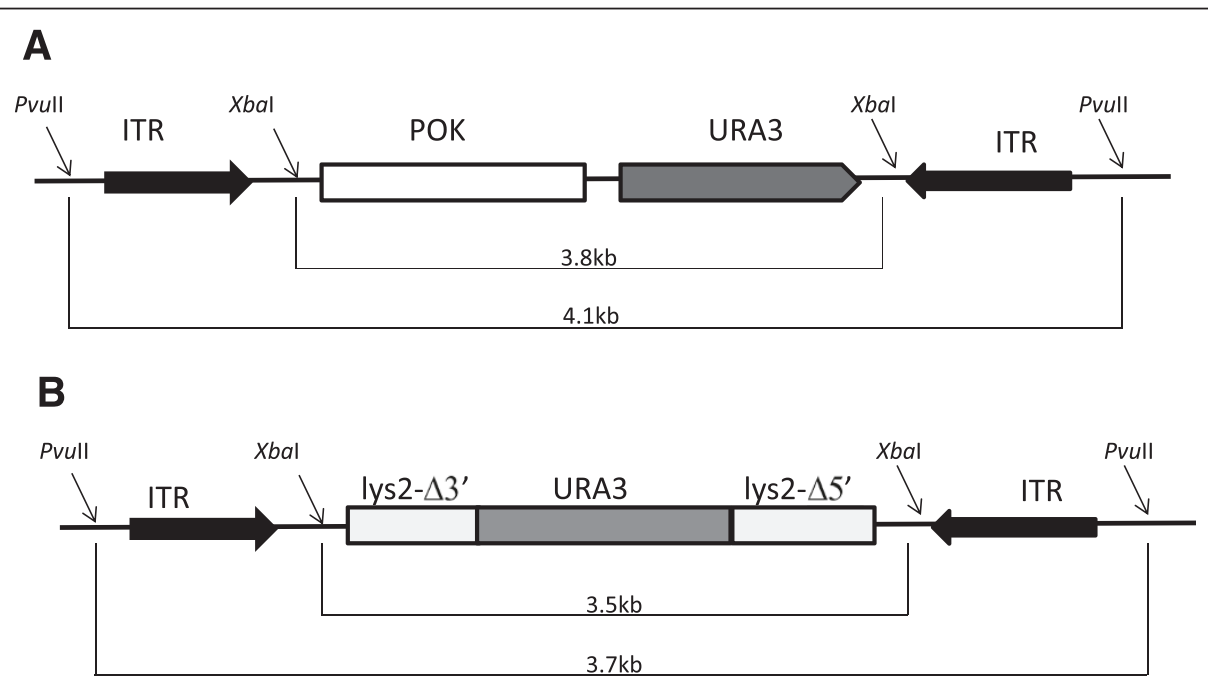

Figure 1 Schematic representations of plasmids carrying the recombinant AAV fragment (rAAV). A) pAAVpokURA. B) pAAVLUL. In both plasmids, restriction with Pvull gives rise to the rAAV fragment containing the ITRs; restriction with Xbal cuts out the ITRs and generates a fragment with no ITR at both ends. 
Table 1 Effect of the AAV ITR sequence on gene targeting and random integration in yeast

\begin{tabular}{llll}
\hline Plasmid & Gene targeting & Random integration & GT/RI \\
\hline ITR-lys2URA3lys2-ITR & $31.0 \pm 11.3(7025)$ & $0.62 \pm 0.37(487)$ & 50.2 \\
lys2URA3lys2 & $35.4 \pm 10.4(6960)$ & $1.82 \pm 0.41(3420)^{*}$ & 19.4 \\
\hline
\end{tabular}

Yeast was transformed with Pvull- or Xbal-restricted PAAVLUL as reported in Materials and Methods. Gene targeting and random integration events are reported as number of URA3 ${ }^{+}$lys $2^{-}$colonies $/ 10^{3}$ transformants per $\mu \mathrm{g}$ of plasmid DNA and $U R A 3^{+} L Y S 2^{+}$colonies $/ 10^{3}$ transformants per $\mu \mathrm{g}$ of plasmid DNA, respectively. The number of transformants per $\mu \mathrm{g}$ of DNA was determined by transformation with $1 \mu \mathrm{g}$ of episomal plasmid DNA. Results are the mean of four independent experiments \pm standard deviation. The number of total colonies is indicated in parentheses. Statistical analysis was performed using Student's $t$ - test. ${ }^{*} p=0.0048$ vs ITR-lys2URA3lys2-ITR.

finger technology $[15,32,33]$. Several studies indicate that AAV mediated gene targeting is affected by homologous recombination genes and that the AAV integration can be dependent on non-homologous end joining [34-37]; however, to our knowledge no comparative study has been performed to understand the role of ITRs and Rep proteins in gene targeting and random integration. Thus, to study the effect of ITRs on yeast gene targeting, we constructed a novel vector called pAAVLUL, containing the LYS2 gene interrupted by URA3 gene and flanked by the ITRs (Figure 1B). As shown in Figure 1B, the gene targeting fragment from the pAAVLUL was generated by two different restriction enzymes in order to keep the ITRs flanking both ends of the fragment, or not.

Overall, gene targeting was not affected by the presence of ITRs (Table 1); however, the random integration increased by almost threefold when ITRs were not present (Table 1). Thus, when ITRs are present, the GT/ RI ratio increased fifty fold because the random integration decreased (Table 1). Southern blot analysis of genomic DNA of eleven $\mathrm{URA}^{+} \mathrm{LYS}^{+}{ }^{+}$random integration clones derived from yeast transformed with ITRs-carrying fragments indicated that ten clones have a single URA3 integration (Figure 2; clones 1, 3, 4, 5, 6, 7, 8, 9, 10, 11).
Although the size of the band is higher than the size of the AAV construct $(3.7 \mathrm{~kb}$ ) (Figure $1 \mathrm{~B})$, three clones out of ten have no ITRs as detected by the hybridization of the blot with ITR probe (Figure 2; clone 4, 5 and 9). Moreover, three clones have two or more copies of the construct, one detected with URA probe (Figure 2, clone 2) and two detected with ITR probe (Figure 2, clone 1 and 3). Clone 2 integrated two copies of the DNA fragment, but only one copy contained ITRs. We considered "rearrangements" those bands which were detected by only one probe (URA3 or ITR) or those with a size smaller than rAAV (3.7 kb, Figure 1B). We can conclude that in six out of eleven clones (54\%) some rearrangement occurred. In order to better understand whether these rearrangements are due to ITRs, we analyzed the genomic DNA of fourteen $\mathrm{URA}^{+} \mathrm{LYS}^{+}{ }^{+}$random integration clones derived from the transformation with no ITR carrying-fragment. Figure 3 shows that nine out of fourteen clones (64\%) contained a single copy of the fragment (Figure 3, clones 2, 3, $5,6,7,8,10,12,14)$ and there was no band lower than $3.5 \mathrm{~kb}$ (the size of the fragment without ITRs, Figure 1B). To make sure that ITRs are really not present in the genomic DNA, we hybridized the filter with the ITR probe. No bands were detected (data not shown). This result suggests that no rearrangement has occurred in absence of ITRs. Finally, we sequenced the junctions in order to see where the gene targeting construct was randomly integrated. By using two primers starting from the two portions of LYS2 gene in the fragment, we were able to sequence four junctions; three junction sites were located on chromosome II right next to the LYS2 locus and one junction was on chromosome XVI. The precise analysis of the sequence did not reveal any preferred junction site. However, it is possible that the homology between the fragment and the genome drives non-homologous integration. Our results clearly indicate that the presence of ITRs flanking the homologous sequence in the gene targeting

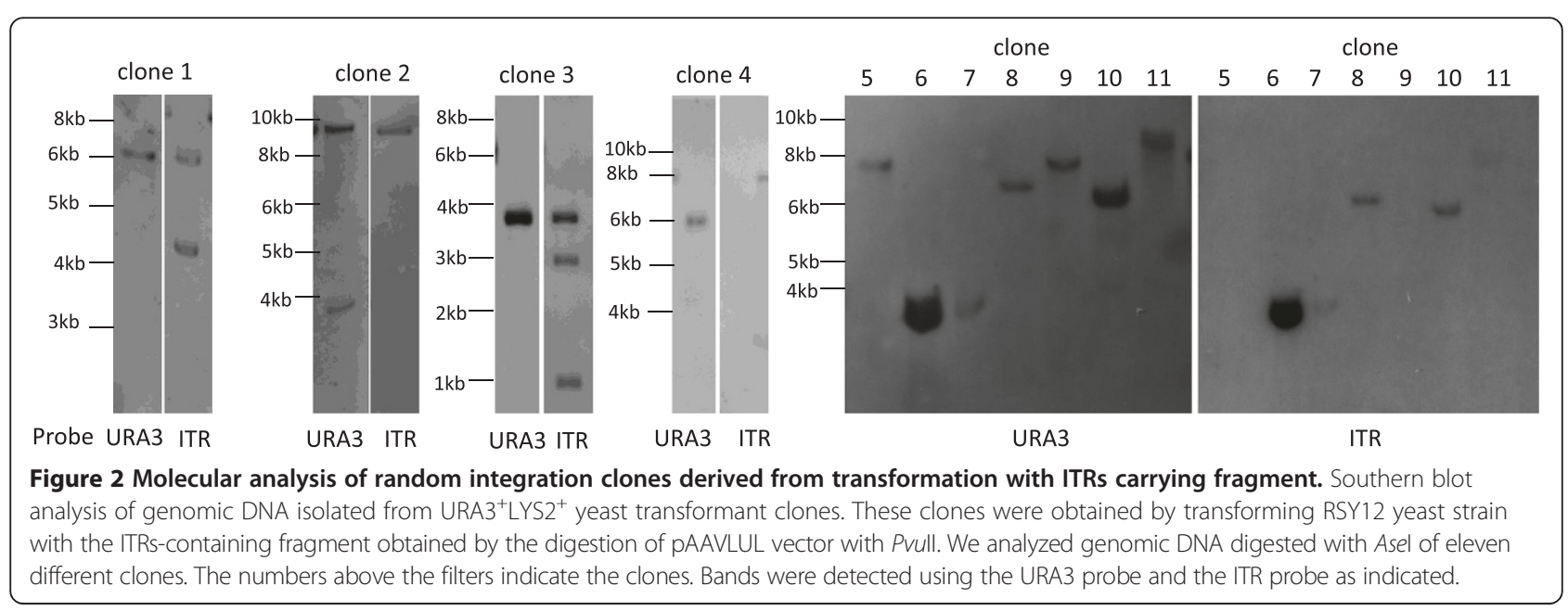




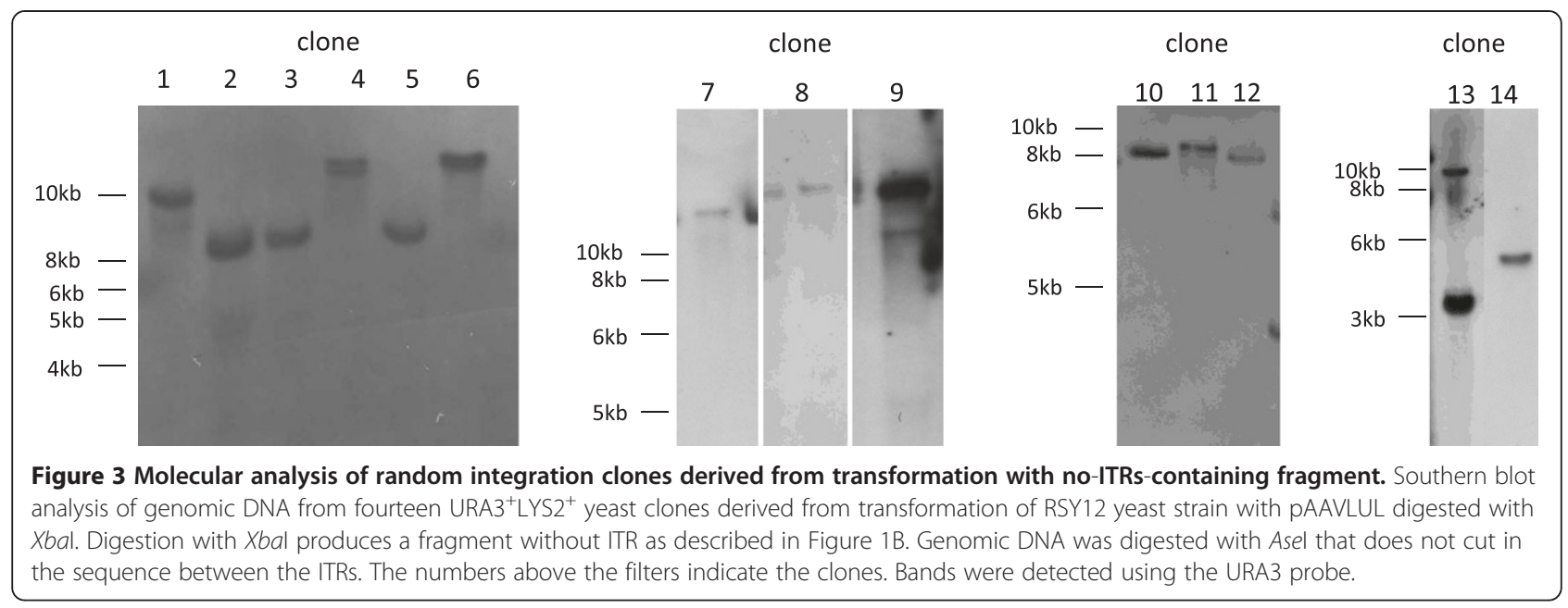

fragment decreased random integration in yeast but determined a higher number of rearrangements.

The expression of Rep proteins increased AAV integration of a non-homologous fragment carrying ITRs

As Rep68 produces a site-specific ssDNA nick in the ITR, we thought that this ssDNA nick could affect both gene targeting and random integration. We used a yeast strain stably expressing all the Rep proteins to determine the effect on both gene targeting and random integration of the ITRs carrying fragment. The expression of Rep proteins is shown in the Western blot in Figure 4A.
When the integration fragment shared homology with the genomic target (LYS2 chromosomal gene), both gene targeting and random integration were not affected by the expression of Rep proteins (Table 2). However, when there is no homology between the fragment and the genome locus (ITR-pokURA-ITR, Figure 1A), the Rep expression significantly increased random integration (see Table 2). Presumably, the ssDNA nick at the level of ITR may be repaired through non-homologous recombination, resulting in an increase in random integration of the vector. Southern blot analysis of the genomic DNA extracted from a total of twelve clones derived

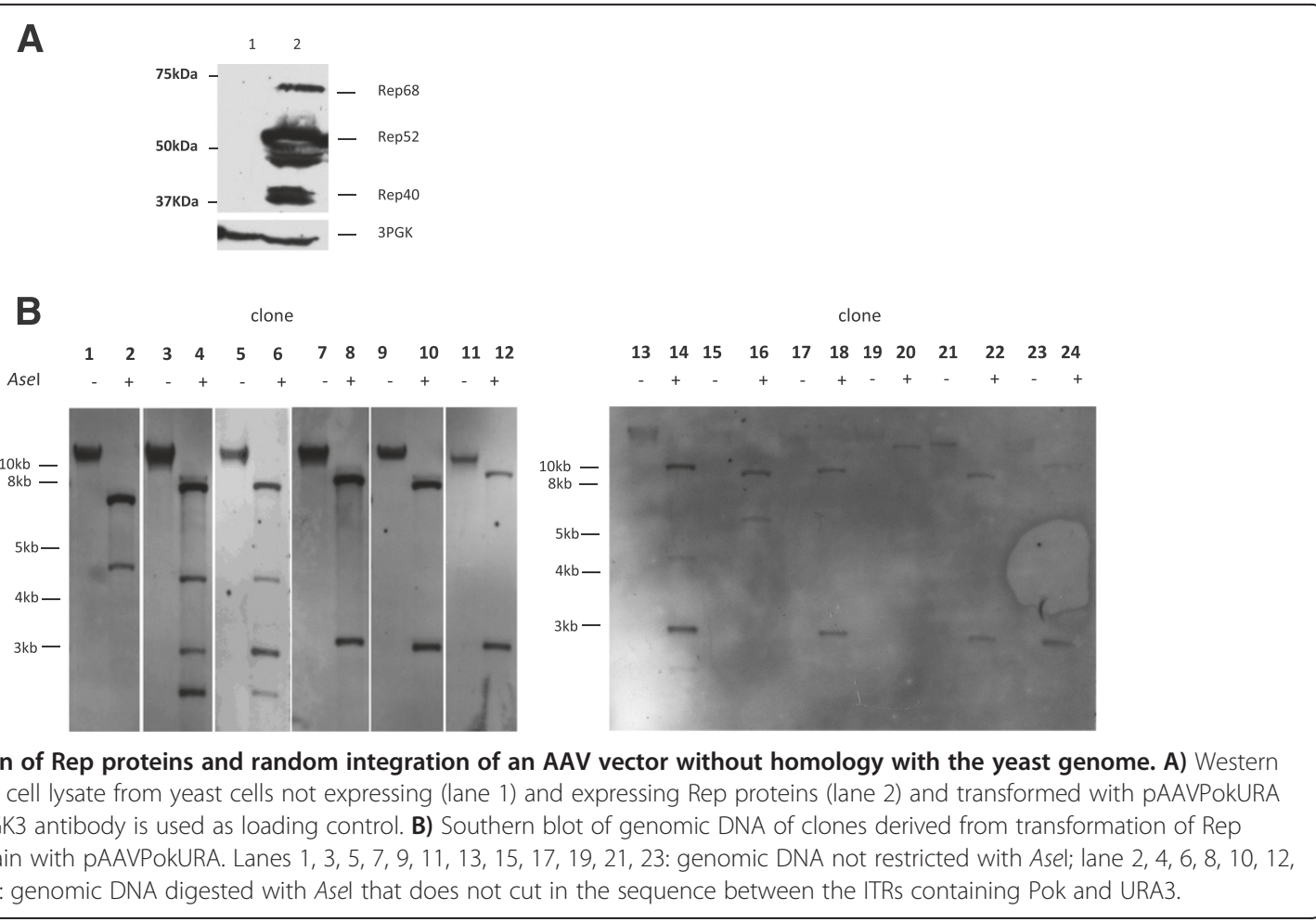


Table 2 Effect of the AAV Rep protein expression on gene targeting and random integration in yeast

\begin{tabular}{llll}
\hline Plasmid & $\begin{array}{l}\text { Gene } \\
\text { targeting }\end{array}$ & $\begin{array}{l}\text { Random } \\
\text { integration }\end{array}$ & GT/RI \\
\hline ITR-Iys2URA3lys2-ITR, No REP & $31.8 \pm 9.8$ & $0.73 \pm 0.39$ & 43.5 \\
ITR-Iys2URA3lys2-ITR, REP & $20.1 \pm 5.9$ & $0.88 \pm 0.49$ & 22.8 \\
ITR-pokURA3-ITR, No REP & $\mathrm{ND}$ & $0.12 \pm 0.08$ & $/$ \\
ITR-pokURA3-ITR, REP & $\mathrm{ND}$ & $1.02 \pm 0.56^{*}$ & / \\
\hline
\end{tabular}

Yeast was transformed with Pvull-restricted pAAVLUL or pAAVpokURA as reported in Materials and Methods. In the case of experiments with PAAVLUL, gene targeting and random integration events are reported as number of URA $3^{+}$lys $2{ }^{-}$colonies $/ 10^{3}$ transformants per $\mu \mathrm{g}$ of plasmid DNA and $U R A 3^{+} L Y S 2^{+}$ colonies $/ 10^{3}$ transformants per $\mu \mathrm{g}$ of plasmid DNA, respectively. Similarly, in the case of pAAVpokURA experiments, non-homologous integration events are reported as total URA $3^{+}$colonies $/ 10^{3}$ transformants per $\mu \mathrm{g}$ DNA. The number of transformants per $\mu \mathrm{g}$ of plasmid DNA was determined by transformation with $1 \mu \mathrm{g}$ of episomal plasmid DNA. Results are the mean of four independent experiments \pm standard deviation. The number of total colonies is indicated in the parentheses. Statistics was performed using Student's $t$-test. ${ }^{*} p=0.0078$ vs ITR-pokURA3-ITR, No REP. ND = not detectable.

from transformation of the yeast strain stably expressing Rep proteins was performed to check the number of stably integrated plasmid copies. It is interesting to note that eleven out of twelve clones contained at least two copies of the fragment (Figure 4B, lanes 2, 4, 6, 8 10, 12, $14,16,22,24)$. This may be important for gene therapy application, where it is preferable to avoid vector random integration in order to prevent rearrangements.

\section{Conclusions}

Our results indicate that the ITRs and Rep proteins may affect AAV genomic random integration when no homology between the vector and the genome is present, and that rearrangements occur. Conversely, the presence of the AAV ITRs at both ends in a gene targeting construct sharing homology with a genomic locus could have an impact on the application of this strategy by significantly decreasing random integration.

\section{Methods \\ Plasmids}

The construction of the plasmid pAAVPokURA, which contains the URA3 marker and the $2.5 \mathrm{~kb}$ Pok stuffer sequence to increase the distance between the ITRs, has been previously reported [20] (Figure 1A). The plasmid pAAVLUL carrying the gene-targeting fragment between the two ITRs (Figure 1B), was constructed as follows: the $2.7 \mathrm{~kb}$ EcoRI-BamHI fragment from pJZ102 [25] was first cloned into the pMCSsub; then, the entire fragment was cut off from pMCSsub with XbaI and inserted directly into the $\mathrm{XbaI}$ site of pSub201 containing the ITRs [20].

\section{Yeast transformation and molecular analysis}

The yeast strain RSY12 (MATa leu2-3,112 his3-11,15 URA3::HIS3) has a complete deletion of the URA3 gene, which was replaced with the HIS3 gene [38]. To evaluate the effect of Rep proteins expression on gene targeting and random integration, we transformed the pAAV vectors in the RSY12 yeast strain containing the vector pG. Rep68 integrated into the genome [20].

Complete (YPAD) and synthetic complete (SC) medium were prepared according to standard procedures. Yeast was transformed with 3-5 $\mu \mathrm{g}$ of plasmid DNA using the standard lithium chloride method with single-stranded DNA as carrier [39]. The vectors pAAVLUL and pAAVpokURA were transformed, digested with either PvuII or XbaI. Transformants were selected on SC-uracil (SC-URA). As the gene targeting events disrupt the chromosomal LYS2 gene by inserting the URA3 marker, the URA3 transformants were replica-plated in SC-lysine-uracil (SC-LYS URA) plates to score for the random integration and gene targeting. In parallel, the same yeast culture was transformed with an episomal plasmid to evaluate the efficiency of transformation per $\mu \mathrm{g}$ of plasmid DNA. The frequency of gene targeting and random integration, calculated by dividing the number of events by the transformation efficiency, was expressed as number of $\mathrm{URA}^{+}$lys $2^{-} / 10^{3}$ and $\mathrm{URA}^{+}$ $\mathrm{LYS}^{+} / 10^{3}$ total transformants per $\mu \mathrm{g}$ of plasmid DNA, respectively. Data were statistically evaluated by Student's $t$-test with computer assistance. Single clones were grown in 5-10 $\mathrm{ml}$ of SC-URA and the genomic DNA isolated using the Master pure yeast DNA purification Kit (Epicentre Biotechnologies). The DNA was digested with AseI, which does not cut in the rAAV fragment, electrophoresed, transferred to a nylon membrane (Roche), and hybridized with DIG-labelled -URA3 and ITR probes according to the standard protocol. DIG-labelled URA3 and ITR were obtained as previously described [20].

Western blot was performed with the monoclonal antibody 303.9 (PROGEN, Germany) and anti-3PGK (Invitrogen) as previously described [20].

To clone the junction sites, the genomic DNA from $\mathrm{URA}^{+}{ }^{\mathrm{LYS}} 2^{+}$clones was digested with SphI and ligated in the SphI site of YEplac181 [40]. Then, the ligation mixture was transformed into competent E.coli. Single ampicillinresistant colonies were grown in selection liquid medium, plasmid DNA extracted and sequenced with these primers: LYS2-UP 5' TCCACTGCCAAGTATAGAA 3' and LYS2LOW 5'GTCATGTGGTAACACTGAA 3'.

\section{Competing interests}

The authors declare no competing interests.

\section{Authors' contributions}

AG and TC conceived of the study and participated in its design and coordination. TC carried out the experimental work and analyzed the data. AG had a major contribution in writing the manuscript. Both authors read and approved the final manuscript.

\section{Acknowledgements}

The authors are grateful to Robert Schiestl for the RSY12 yeast strain and the pJZ102 plasmid. The authors wish to thank Ana Backovic and Lidia Balestri 
for technical assistance and helpful suggestions. They are grateful to Marcella Simili for reading and editing the final version of the manuscript.

\section{Funding}

This work was supported by Grant n. GGP09166 assigned by Telethon-Italy to AG. The funder had no role in study design, data collection, decision to publish or preparation of the manuscript.

\section{Received: 16 October 2013 Accepted: 6 February 2014}

Published: 13 February 2014

\section{References}

1. Sedivy JM, Dutriaux A: Gene targeting and somatic cell genetics-a rebirth or a coming of age? Trends Genet 1999, 15:88-90.

2. Porteus $\mathrm{MH}$, Baltimore $\mathrm{D}$ : Chimeric nucleases stimulate gene targeting in human cells. Science 2003, 300:763.

3. Hockemeyer D, Wang H, Kiani S, Lai CS, Gao Q, Cassady JP, Cost GJ, Zhang $L$, Santiago Y, Miller JC, et al: Genetic engineering of human pluripotent cells using TALE nucleases. Nat Biotechnol 2011, 29:731-734.

4. Miller JC, Tan S, Qiao G, Barlow KA, Wang J, Xia DF, Meng X, Paschon DE, Leung E, Hinkley SJ, et al: A TALE nuclease architecture for efficient genome editing. Nat Biotechnol 2011, 29:143-148.

5. Urnov FD, Rebar EJ, Holmes MC, Zhang HS, Gregory PD: Genome editing with engineered zinc finger nucleases. Nat Rev Genet 2010, 11:636-646.

6. Pattanayak V, Ramirez CL, Joung JK, Liu DR: Revealing off-target cleavage specificities of zinc-finger nucleases by in vitro selection. Nat Methods 2011, 8:765-770.

7. Gabriel R, Lombardo A, Arens A, Miller JC, Genovese P, Kaeppel C, Nowrouzi A, Bartholomae CC, Wang J, Friedman G, et al: An unbiased genome-wide analysis of zinc-finger nuclease specificity. Nat Biotechnol 2011, 29:816-823.

8. van Nierop GP, de Vries AA, Holkers M, Vrijsen KR, Goncalves MA: Stimulation of homology-directed gene targeting at an endogenous human locus by a nicking endonuclease. Nucleic Acids Res 2009, 37:5725-5736.

9. Di Primio C, Galli A, Cervelli T, Zoppe M, Rainaldi G: Potentiation of gene targeting in human cells by expression of Saccharomyces cerevisiae Rad52. Nucleic Acids Res 2005, 33:4639-4648.

10. Kalvala A, Rainaldi G, Di Primio C, Liverani V, Falaschi A, Galli A: Enhancement of gene targeting in human cells by intranuclear permeation of the Saccharomyces cerevisiae Rad52 protein. Nucleic Acids Res 2010, 38:e149.

11. Russell DW, Hirata RK: Human gene targeting by viral vectors. Nat Genet 1998, 18:325-330.

12. Weitzman MD, Linden RM: Adeno-associated virus biology. Methods MolBiol 2011, 807:1-23

13. Hendrie PC, Russell DW: Gene targeting with viral vectors. MolTher 2005, 12:9-17.

14. Vasileva A, Jessberger R: Precise hit: adeno-associated virus in gene targeting. Nat Rev Microbiol 2005, 3:837-847

15. Ellis BL, Hirsch ML, Porter SN, Samulski RJ, Porteus MH: Zinc-finger nuclease-mediated gene correction using single AAV vector transduction and enhancement by Food and Drug Administration-approved drugs. Gene Ther 2013, 20:35-42.

16. Handel EM, Gellhaus K, Khan K, Bednarski C, Cornu TI, Muller-Lerch F, Kotin RM, Heilbronn R, Cathomen T: Versatile and efficient genome editing in human cells by combining zinc-finger nucleases with adeno-associated viral vectors. Hum Gene Ther 2012, 23:321-329.

17. Petek LM, Russell DW, Miller DG: Frequent endonuclease cleavage at off-target locations in vivo. MolTher 2010, 18:983-986.

18. Gellhaus K, Cornu TI, Heilbronn R, Cathomen T: Fate of recombinant adeno-associated viral vector genomes during DNA double-strand break-induced gene targeting in human cells. Hum Gene Ther 2010, 21:543-553.

19. Miller DG: AAV-mediated gene targeting. Methods MolBio/ 2011, 807:301-315.

20. Cervelli T, Backovic A, Galli A: Formation of AAV single stranded DNA genome from a circular plasmid in Saccharomyces cerevisiae. PLoS One 2011, 6:e23474.

21. Ward P, Urcelay E, Kotin R, Safer B, Berns Kl: Adeno-associated virus DNA replication in vitro: activation by a maltose binding protein/Rep 68 fusion protein. J Virol 1994, 68:6029-6037.

22. Surosky RT, Urabe M, Godwin SG, McQuiston SA, Kurtzman GJ, Ozawa K, Natsoulis G: Adeno-associated virus Rep proteins target DNA sequences to a unique locus in the human genome. J Virol 1997, 71:7951-7959.
23. Im DS, Muzyczka N: The AAV origin binding protein Rep68 is an ATP-dependent site-specific endonuclease with DNA helicase activity. Cell 1990, 61:447-457.

24. Im DS, Muzyczka N: Partial purification of adeno-associated virus Rep78, Rep52, and Rep40 and their biochemical characterization. J Virol 1992, 66:1119-1128.

25. Schiestl RH, Zhu J, Petes TD: Effect of mutations in genes affecting homologous recombination on restriction enzyme-mediated and illegitimate recombination in Saccharomyces cerevisiae. Mol Cell Biol 1994, 14:4493-4500

26. Galli A, Hafer K, Cervelli T, Schiestl RH: The pol3-t hyperrecombination phenotype and DNA damage-induced recombination in Saccharomyces cerevisiae is RAD50 dependent. J Biomed Biotechnol 2009, 2009:312710.

27. Karpenshif $Y$, Bernstein KA: From yeast to mammals: recent advances in genetic control of homologous recombination. DNA Repair (Amst) 2012, 11:781-788

28. Krejci L, Altmannova $V$, Spirek M, Zhao X: Homologous recombination and its regulation. Nucleic Acids Res 2012, 40:5795-5818.

29. Daley JM, Palmbos PL, Wu D, Wilson TE: Nonhomologous end joining in yeast. Annu Rev Genet 2005, 39:431-451.

30. Chan $\mathrm{CY}$, Schiestl RH: Rad1, rad10 and rad52 mutations reduce the increase of microhomology length during radiation-induced microhomology-mediated illegitimate recombination in saccharomyces cerevisiae. Radiat Res 2009, 172:141-151.

31. Dicarlo JE, Norville JE, Mali P, Rios X, Aach J, Church GM: Genome engineering in Saccharomyces cerevisiae using CRISPR-Cas systems. Nucleic Acids Res 2013, 41:4336-4343.

32. Khan IF, Hirata RK, Russell DW: AAV-mediated gene targeting methods for human cells. Nat Protoc 2011, 6:482-501.

33. Luo Y, Kofod-Olsen E, Christensen R, Sorensen CB, Bolund L: Targeted genome editing by recombinant adeno-associated virus ( $\mathrm{rAAV}$ ) vectors for generating genetically modified pigs. J Genet Genomics 2012, 39:269-274.

34. Vasileva A, Linden RM, Jessberger R: Homologous recombination is required for AAV-mediated gene targeting. Nucleic Acids Res 2006, 34:3345-3360

35. Paulk NK, Loza LM, Finegold MJ, Grompe M: AAV-mediated gene targeting is significantly enhanced by transient inhibition of nonhomologous end joining or the proteasome in vivo. Hum Gene Ther 2012, 23:658-665.

36. Cataldi MP, McCarty DM: Differential effects of DNA double-strand break repair pathways on single-strand and self-complementary adeno-associated virus vector genomes. J Virol 2010, 84:8673-8682.

37. Daya S, Cortez N, Berns Kl: Adeno-associated virus site-specific integration is mediated by proteins of the nonhomologous end-joining pathway. J Virol 2009, 83:11655-11664.

38. Schiestl RH, Petes TD: Integration of DNA fragments by illegitimate recombination in Saccharomyces cerevisiae. ProcNat/AcadSci USA 1991 88:7585-7589

39. Gietz RD, Schiestl RH: High-efficiency yeast transformation using the LiAc/ SS carrier DNA/PEG method. Nat Protoc 2007, 2:31-34.

40. Gietz RD, Sugino A: New yeast-Escherichia coli shuttle vectors constructed with in vitro mutagenized yeast genes lacking six-base pair restriction sites. Gene 1988, 74:527-534.

doi:10.1186/1471-2199-15-5

Cite this article as: Galli and Cervelli: Inverted terminal repeats of adeno-associated virus decrease random integration of a gene targeting fragment in Saccharomyces cerevisiae. BMC Molecular Biology 2014 15:5. 